\title{
Assessoria médica e de resgate em expedições e esportes em áreas remotas
}

\author{
Clemar Corrêa da Silva
}

Silva CC. Assessoria médica e de resgate em expedições e esportes em áreas remotas. Rev Med (São Paulo). 2012 jan.mar.;91(1):19-24.

RESUMO: Expedições e atividades esportivas em áreas remotas e hostis fazem parte da história da humanidade e são cada vez mais comuns. Esses ambientes apresentam riscos importantes para a segurança dos participantes e mortes não são raras. Equipes médicas e de busca e salvamento surgiram no sentido de trazer mais segurança a tais atividades. Este texto procura mostrar as características de tais atividades bem com da chamada Wilderness Medicine.

DESCRITORES: Medicina selvagem/recursos humanos; Medicina selvagem/organização \& administração; Busca e resgate; Equipe de busa e resgate; Esportes/classificação; Sobrevivência; Logística.

$\mathrm{O}$ ser humano, desde suas origens, teve a necessidade de se deslocar geograficamente, inicialmente à procura de alimento e abrigo, mais tarde para desbravamento de territórios desconhecidos por terra ou mar bem como conquistas territoriais com atividades bélicas, nos últimos séculos como parte de expedições e nas últimas décadas participando dos chamados esportes de aventura. Tais atividades sempre implicaram em riscos, principalmente pelos perigos inerentes à geografia, clima, animais perigosos, doenças, enfrentamento de populações potencialmente hostis e falta de suprimentos como água e comida. A História documentou centenas de expedições buscando locais cada vez mais remotos e atualmente conhecemos incontáveis competições envolvendo esportes também em áreas distantes da civilização, sempre inóspitas. Mesmo com todo o desenvolvimento tecnológico de nossa época, o perigo nessas situações é frequente e o homem é o único animal que procura isso propositadamente, sem qualquer necessidade de procura de alimento, preservação da espécie, delimitação de território ou melhora de condições para habitação. No entanto, desde os primeiros hominídeos, há mais de 3 milhões de anos, esse espírito expedicionário, gerenciando limitações físicas, psicológicas e técnicas, com grandes riscos para a vida, teve papel importante para o aprimoramento e perpetuação da espécie humana. A questão muito atual, de por que o homem enfrenta o desconhecido e o perigo, ludibriando ou mesmo saboreando o risco e o medo, tem várias vertentes de respostas. Linhas de pensamento e de pesquisa, principalmente antropológicas, psicológicas e médicas, têm analisado tal questão. Sabe-se hoje da existência de determinantes genéticos que impelem certas pessoas a procurar o perigo e a excitação nas atividades de alto risco, não só no esporte. Sabe-se também que as pessoas que procuram emoções fortes e enfrentam o perigo teriam diferentes quantidades (ou formas de ação) de substâncias que controlam o prazer, a calma, a iniciativa, o dinamismo, o enfrentamento de desafios, o medo, etc.. E como citado acima, esse espírito

Coordenador - Grupo de Tumores Cerebrais. Divisão de Clínica Neurocirúrgica - Departamento de Neurologia. Hospital das Clínicas da Faculdade de Medicina da Universidade de São Paulo. São Paulo, SP, Brasil.

Endereço para correspondência: e-mail: waimea@uol.com.br 
aventureiro ou expedicionário foi fundamental na perpetuação da espécie humana.

Em todo o mundo surgiram associações, empresas e equipes especializadas em resgate e assessoria médica para grandes expedições e esportes de aventura, nas chamadas áreas remotas. Tal tipo de atividade inegavelmente tem suas bases nas equipes de Medicina Militar que atendem, há séculos, operações de tropas em batalhas e guerras. Tal trabalho tem também semelhança com equipes médicas de delegações esportivas que participam de grandes competições.

No Brasil, esse tipo de preocupação médica teve seus primórdios, de forma muito modesta, nas chamadas Entradas e Bandeiras, desbravadoras de territórios, na época do Brasil Colônia. Séculos depois, equipes médicas acompanharam atividades militares em várias guerras. Com relação a expedições e esportes chamados "de aventura" em áreas remotas, especialistas desenvolveram o que é conhecido hoje como Wilderness Medicine. Essa área médica é hoje muito difundida na Europa, Estados Unidos e Canadá. No Brasil ainda é pouco divulgada e os atendimentos de busca, salvamento e resgate ainda são feitos, em sua maioria, por equipes do Corpo de Bombeiros, Polícia Militar e Forças Armadas. Em algumas áreas de nosso país há pequenos grupos de pessoas, geralmente voluntários, que procuram atender situações de resgate em alguns parques ambientais. Em 1993, assessorando competições esportivas de risco em áreas remotas, podemos dizer que a primeira equipe médica brasileira surgiu com o trabalho de alguns médicos aqui do Hospital das Clínicas da Faculdade de Medicina da Universidade de São Paulo. Naquele ano foi criado o Rally dos Sertões, hoje o segundo maior rally motorizado do mundo (sendo o primeiro o conhecido Rally Dakar). Naquela primeira edição do Rally dos Sertões, a equipe médica responsável foi formada por 04 médicos: Ricardo Campedelli (ortopedista do Instituto de Ortopedia e Traumatologia), Emílio Pigozzi (da Divisão de Cirurgia Plástica), Claudio Birolini (do Departamento de Clínica Cirúrgica) e Clemar Corrêa da Silva (Divisão de Clínica Neurocirúrgica), autor deste texto. Tal equipe desenvolveu as primeiras estratégias de logística e equipamento médico para assessoramento esportivo com tal perfil. Essa equipe cresceu muito nestes 20 anos, com grande aprimoramento de sua estrutura. Hoje, com mudanças em seu quadro médico e paramédico, tal equipe já acumulou assessoria médica em mais de 120 eventos esportivos em áreas de difícil acesso, dentro e fora do Brasil, sob a coordenação do autor deste texto. Ressalte-se que esse tipo de medicina tem amplo campo de trabalho no exterior, mormente pela postura de organizadores de eventos que entendem como essencial a contratação de equipes especializadas na segurança médica de eventos de risco no ambiente outdoor. No Brasil, infelizmente, poucos organizadores de provas têm tal consciência e raramente destinam parte de suas verbas para contratação de boas equipes para esse tipo de trabalho médico.

Neste texto, procuraremos resumir as bases desse tipo de assessoria médica nas expedições e esportes de aventura.

\section{Principais características desse tipo de evento}

$>$ Forças de grande magnitude causando as lesões traumáticas, principalmente quando o evento envolve atividades em alta velocidade ou grandes alturas.

$>$ Condições naturais agressivas: clima, topografia, animais, doenças, etc.

$>$ Busca e resgate difíceis tanto logística quanto tecnicamente.

$>$ Dificuldade no atendimento do paciente, uma vez que o mesmo pode estar em alta montanha, deserto, ambiente aquático, florestas, etc.

$>$ Dificuldade de comunicação, exigindo para isso formas elaboradas de emissão de sinal para chamados médicos e comunicação entre os profissionais da equipe médica e de resgate.

$>$ Longas distâncias de hospitais e similares, o que torna ainda mais demorado o início do tratamento definitivo para as vítimas.

\section{Principais exigências para as equipes médicas}

$>$ Analisar o perfil da prova em detalhes, principalmente o tipo de modalidade, idade e nível de performance dos participantes e geografia local.

$>$ Estudar a epidemiologia da região a ser percorrida, em termos de doenças (e imunizações necessárias), animais perigosos, etc.

$>$ Analisar a estrutura médica próxima do percurso, principalmente a existência de unidades hospitalares para a recepção de vítimas mais graves.

$>$ Montar a equipe médica, procurando reunir especialistas de várias áreas.

> Disponibilizar transporte compatível com o perfil da prova, seja ele veículos $4 \times 4$, barcos, jet-skis, motos, quadriciclos, helicópteros, etc.

$>$ Elaborar detalhadamente a logística de atendimento, visando oferecer a melhor cobertura possível do evento e minimizando o chamado "temporesposta", que é o tempo entre o chamado para um 
atendimento médico e o atendimento propriamente dito.

> Promover "briefings" antes do evento, no sentido de expor as características do mesmo (principalmente seus riscos) e ações das equipes médicas e de resgate.

$>$ Estar aptas a antecipar diagnósticos difíceis, sem equipamentos especializados, principalmente pelo fato da vítima muitas vezes ter suas lesões decorrentes da combinação de trauma, ação de fatores do ambiente outdoor e exaustão física e psicológica.

\section{Requisitos do Médico}

$>$ Conhecer peculiaridades das modalidades esportivas envolvidas. Geral.

$>$ Ter bons conhecimentos de Medicina

$>$ Conhecer Wilderness Medicine.

$>$ Ter sólida formação em Medicina PréHospitalar.

$>$ Ter bons conhecimentos de Medicina do Esporte.

$>$ Ter domínio de técnicas de resgate em condições difíceis.

$>$ Conhecer as bases da sobrevivência em ambientes hostis.

$>$ Ter desenvoltura com equipamentos, mapas, técnicas e equipamentos de "navegação", principalmente bússolas e GPS.

$>$ Estar familiarizado com os vários meios de comunicação e rastreamento (rádios, telefonia satelital, outros dispositivos eletrônicos de monitoramento de movimento dos participantes, etc.).

$>$ Ter domínio de técnicas de pilotagem "off - road" de veículos motorizados e veículos aquáticos.

$>$ Ter bom preparo físico e excelente estabilidade emocional.

$>$ Ser "pró-ativo", ou seja, estar sempre empenhado em prever situações, antecipar ações e estratégias e criar soluções eficientes.

As modalidades esportivas e expedições incluem atividades em água, terra e ar. Podem envolver inúmeros tipos de esportes, incluindo caminhada, corrida, natação, mergulho, escalada, remo, vela, pilotagem de vários tipos de veículos, paraquedismo, voo livre, e outros, normalmente utilizando mapas e equipamentos de navegação. Cada esporte oferece riscos específicos. Por exemplo, o mergulhador enfrentará os riscos das doenças do mergulho e correntezas, o escalador, as baixas temperaturas, hipóxia, nevascas e quedas de grandes alturas. Quanto ao piloto de rallies, terá principalmente o risco de acidentes em alta velocidade. Quanto às expedições, o que as caracteriza é sua duração, a exposição ao ambiente hostil e a distância de grandes centros urbanos. Obviamente, as condições meteorológicas influem diretamente nos riscos, bem como doenças próprias da região, insetos, animais peçonhentos e de grande porte.
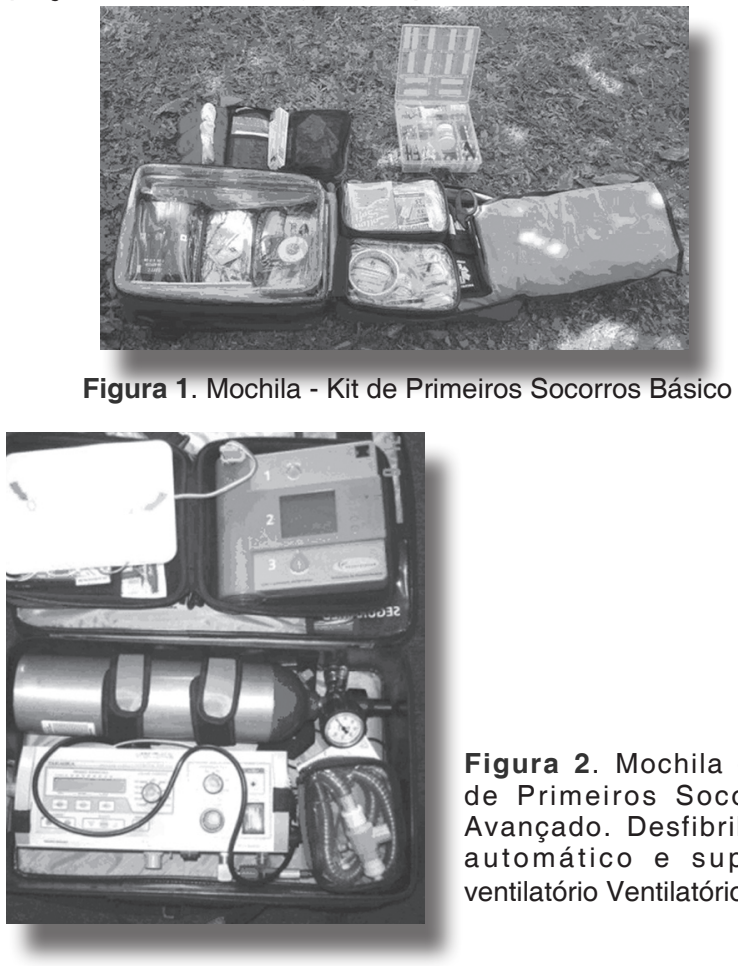

Figura 2. Mochila - Kit de Primeiros Socorros Avançado. Desfibrilador automático e suporte ventilatório Ventilatório

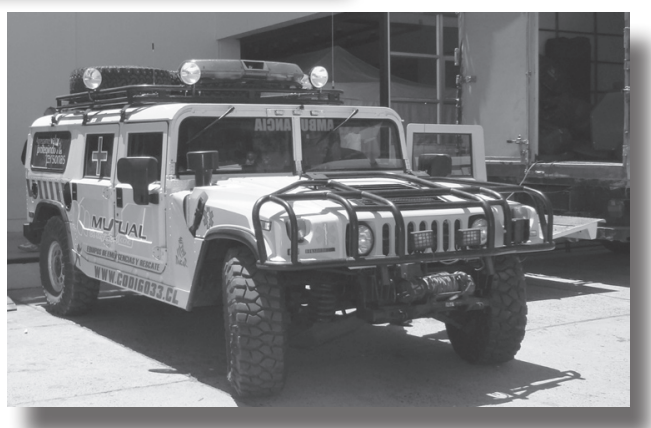

Figura 3. Ambulância "off-road" - Rally Dakar

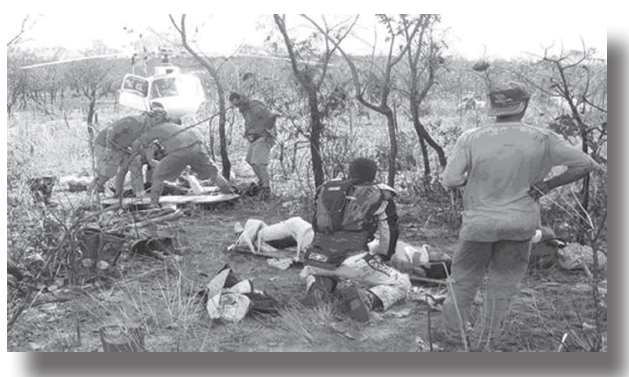

Figura 4. Cenário de atendimento médico e resgate - Rally dos Sertões 


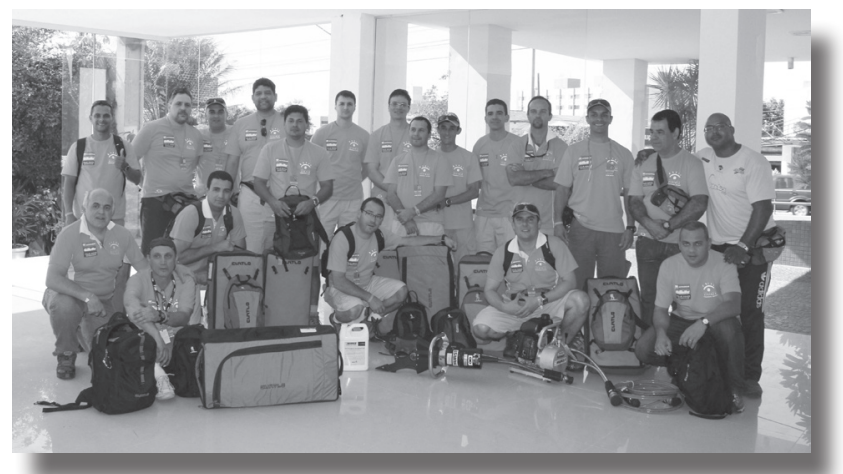

Figura 5. Equipe médica - Rally dos Sertões

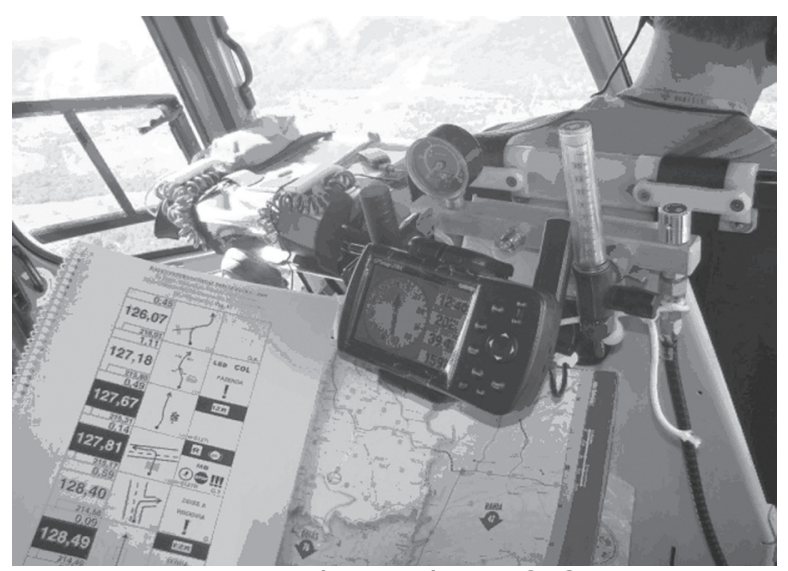

Figura 7. Interior de helicóptero médico - GPS, mapas e equipamentos médicos

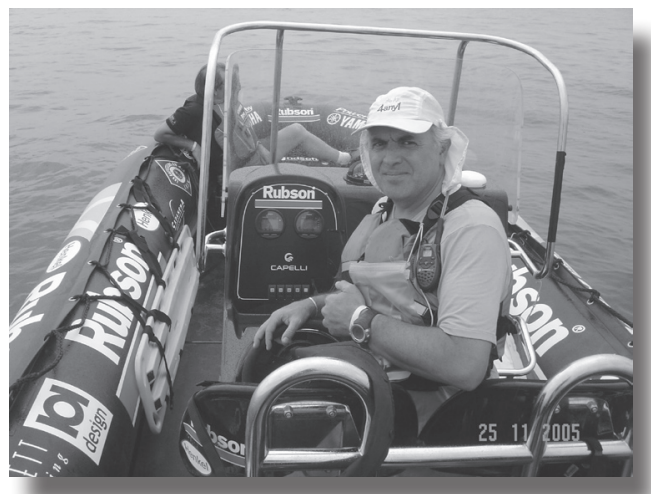

Figura 9. Barco rápido de atendimento médico Rubson Raid Turquoise

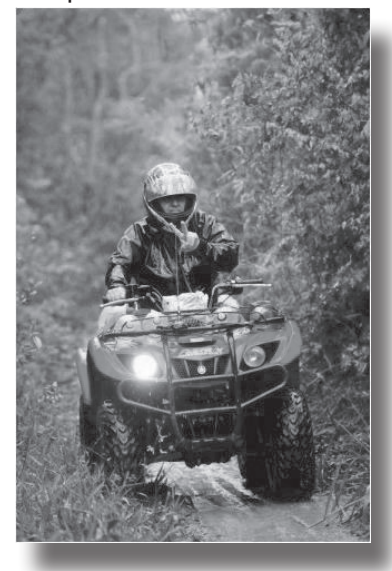

Figura 10. Quadriciclo de atendimento médico

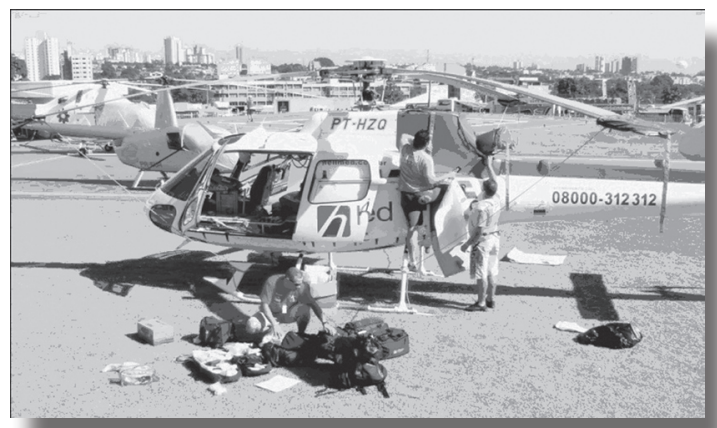

Figura 6. Preparo e checagem de helicóptero médico

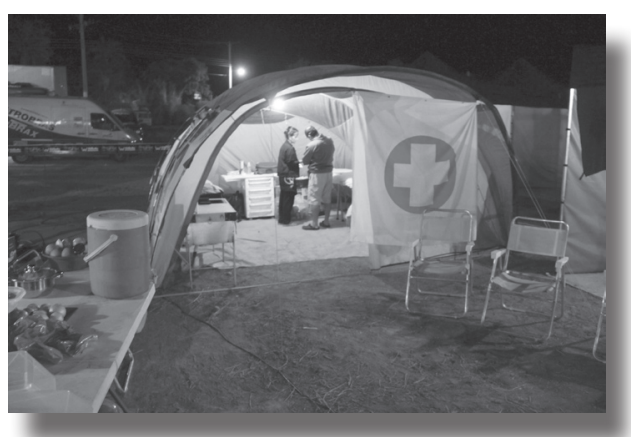

Figura 8. Posto Médico Avançado - Rally dos Sertões

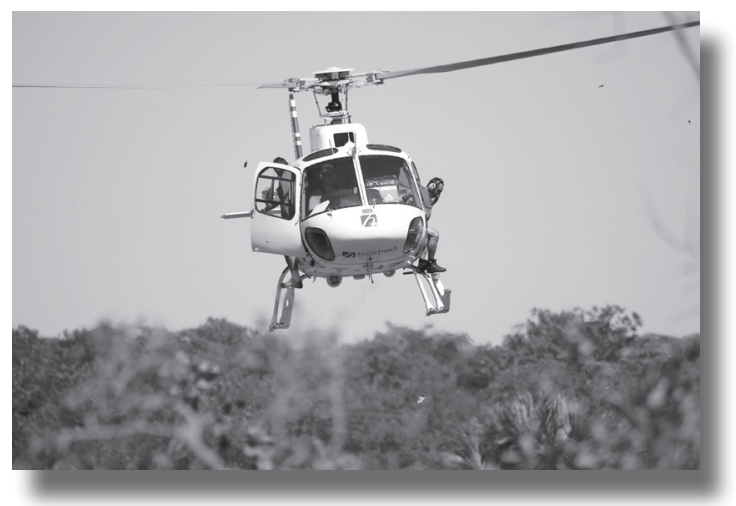

Figura 11. Helicóptero médico preparando pouso em ambiente outdoor

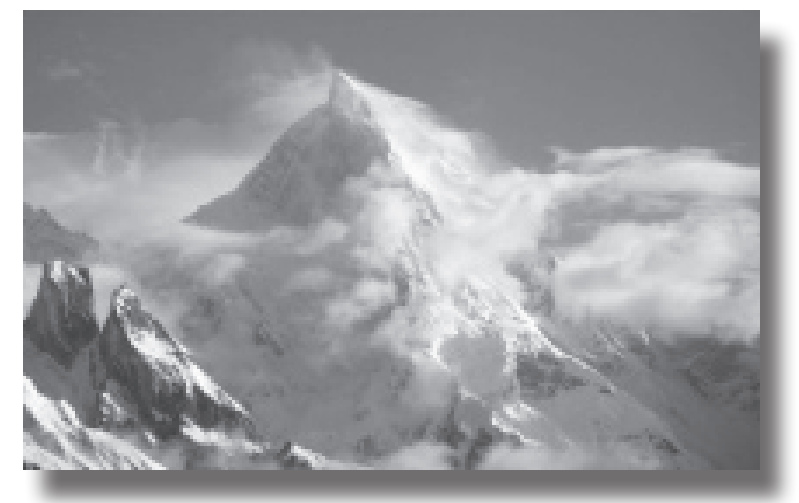

Figura 12. Montanha K2 - um dos mais inóspitos ambientes do planeta 


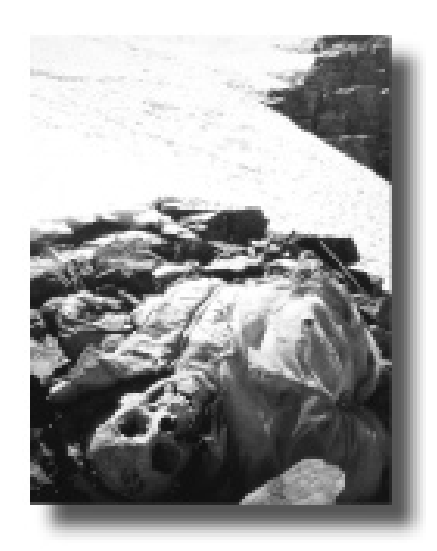

Figura 13. Restos mortais de montanhista não resgatado

\section{A logística de atendimento}

Esse é outro item que demanda detalhada análise do percurso e de inúmeras outras características do evento. A disposição e movimentação da equipe médica e de resgate deve ser de tal forma que permita cobrir da melhor forma possível a extensão do trajeto e possa atender um chamado médico com rapidez. Devem ser estabelecidas bases ou postos médicos desmontáveis e itinerantes, no sentido de permitir avaliações e atendimentos mais elaborados em vários locais ao longo de dias, semanas ou meses. O transporte deve contemplar vários tipos de veículos, que podem incluir ambulâncias "offroad", vários tipos de embarcações, jet-skis, motos, quadriciclos e helicópteros de resgate. Há situações onde o melhor transporte são cavalos ou mulas, pelo acesso não ser possível por veículos motorizados (mesmo helicópteros).

$O$ resgate nem sempre é feito pelas equipes médicas, mas sim por pessoal especializado em busca e salvamento, que pode incluir apenas paramédicos. Vale frisar que o risco sempre existe para as próprias equipes de resgate e médicas.

Normalmente, a formação de uma boa equipe médica e de resgate é o item mais difícil, uma vez que deve reunir pessoas competentes tecnicamente, resistentes física e psicologicamente e que suportem com tranquilidade várias outras adversidades e desconfortos.

O material médico e de busca/salvamento é normalmente volumoso, devendo ser acondicionado em malas de vários tipos e tamanhos e que suportem impactos, umidade e calor, principalmente.

A sistematização do atendimento médico deve seguir os principais protocolos internacionais, entre eles o PHTLS (Pre Hospital Trauma Life Support), o ATLS (Advanced Trauma Life Support), o ACLS (AvancedCardiac Life Support) e o AWLS (AdvancedWilderness Life Support).

\section{A comunicação}

O ambiente dessas provas geralmente não recebe sinais para telefonia celular comum. Além disso, a comunicação por rádios, telefonia satelital e outros sinais eletrônicos costuma ser rápida e permite que uma mensagem ou sinal seja simultaneamente ouvida por várias pessoas. Obviamente, a comunicação é importante não apenas entre as pessoas das equipes médicas e de resgate, mas principalmente entre a vítima e tais equipes. Assim, há várias formas de acionamento médico pela vítima, que inclusive pode estar inconsciente muitas vezes. Deve haver um eficiente sistema de emissão de sinais de alarme, recepção e decodificação desse sinal, identificação do local da emergência, rastreamento das vítimas e equipes médicas e de resgate, bem como orientação precisa para a busca, salvamento e atendimento médico. Obviamente, o detalhamento desses vários sistemas foge da intenção deste texto.

\section{0 atendimento médico propriamente dito}

Ao chegar próximo ao local da ocorrência, o acessoà vitima pode ser extremamente difícil e demanda técnicas e táticas muitas vezes complexas. O cenário deve ser cuidadosamente avaliado, uma vez que muitas vezes pode ser também de alto risco para as equipes de salvamento, como já frisado. Uma adequada estratégia de acesso ao local e à vitima deve ser rapidamente estabelecida, bem como a melhor forma de atendimento e transporte da mesma. É comum ser necessário obtenção de acesso venoso, controle de sangramentos, imobilizações e entubaçãoorotraqueal. Mais uma vez, o material de resgate e médico deve ser abrangente e de fácil transporte, uma vez que deve ser levado até a vítima. $\mathrm{O}$ diagnóstico exato, amparado por equipamentos especializados pode demorar horas a dias, principalmente pelo fato da vítima muitas vezes ter suas lesões decorrentes da combinação de trauma, ação de fatores do ambiente outdoor e exaustão física e psicológica. Essas características exigem, portanto, grande experiência e conhecimento médico das equipes que atendem a situação. Uma vez atendida, a vítima deve ser evacuada por veículos específicos em direção a um posto médico avançado ou ambiente hospitalar. Principalmente quando em horários noturnos, sem a possibilidade de uso de helicópteros, a vítima pode ter que ser carregada em maca por horas, o que demanda enorme desgaste para a mesma e para a equipe de resgate. Uma vez no posto médico, a situação é melhor avaliada e pode ser necessário o translado para um ambiente hospitalar, muitas vezes distante centenas de quilômetros. 
Cumpre ressaltar que principalmente em eventos de caráter expedicionário, como grandes travessias oceânicas, escaladas de alta montanha e excursões para locais extremamente remotos, o resgate pode ser inviável e a vítima sofrerá as consequências óbvias. É comum a mídia divulgar situações onde alpinistas, velejadores, mergulhadores e aventureiros sofreram graves acidentes e nunca tiveram seus corpos resgatados.

\section{CONCLUSÃO}

A Wilderness Medicine e as operações de busca e resgate para expedições e esportes em áreas remotas constituem um tipo de assessoria médica que demanda complexa logística, equipamento sofisticado e equipes altamente treinadas. Tal equipe deve ser multidisciplinar e ter aprimorado treinamento não apenas médico, mas também em técnicas de comunicação, transporte, resgate e sobrevivência. Seus elementos devem ter boa sociabilidade, principalmente pelo convívio por dias a meses em ambiente inóspito e sob vários níveis e tipos de stress. A dificuldade do diagnóstico de vítimas muitas vezes graves e nesse ambiente sem suporte hospitalar e laboratorial exige das equipes alta competência. A escolha de uma equipe com essas características e a complexa logística de atendimento constituem os itens mais difíceis na elaboração de tal assessoria médica.

\section{REFERÊNCIAS}

Este texto foi baseado no conjunto de experiências do autor no exercício da Wilderness Medicine, bem como nas descrições de alguns livros. Na literatura médica há artigos que descrevem particularidades da Wilderness Medicine, mas o autor julga mais adequado citar outros tipos de fontes (abaixo) que possam servir de consulta para o leitor interessado em aprimorar seus conhecimentos no assunto.

Sites especializados:

http://www.nols.edu/wmi/

http://www.wms.org/

http://www.awls.org/

http://www.wilderness-medicine.com/

http://www.wildmed.ca/

http://www.ismmed.org/

http://www.remotemedical.com/

http://www.wildmedcenter.com/

Livros e capítulos de livros:

Auerbach PS. Wilderness medicine. 6th ed. Elsevier; 2011.

Ashcroft F. A vida no limite - a ciência da sobrevivência. Rio de Janeiro: Jorge Zahar Editor; 2001.

Birolini C, Silva CC. Atendimento de trauma em ambiente inóspito e hostil. In: Pogetti R, Fonte B, Birolini D. Cirurgia do trauma. São Paulo: Roca; 2007. p.545-8.

NOTA: As fotos utilizadas neste artigo: Figuras 1 a 9, são de autoria de Clemar Corrêa da Silva; as Figuras 10 a 13 , infelizmente não identificamos, para contato, os autores das fotos. 